\title{
In vitro evaluation of bovine lactoferrin potential as an anticancer agent
}

\author{
Yunlei Zhang ${ }^{\text {a, c }}$, Cristovao F. Lima ${ }^{\text {b }}$, Ligia R. Rodrigues ${ }^{\text {a, * }}$ \\ ${ }^{\text {a }}$ CEB - Centre of Biological Engineering, University of Minho, 4710-057 Braga, Portugal \\ ${ }^{\mathrm{b}}$ CITAB - Centre for the Research and Technology of Agro-Environmental and Biological Sciences, Department of Biology, University of Minho, $4710-057$ \\ Braga, Portugal \\ ${ }^{\mathrm{c}}$ College of Life Science, Hunan Provincial Key Laboratory of Microbial Molecular Biology - State Key Laboratory Breeding Base of Microbial Molecular \\ Biology, Hunan Normal University, Changsha 410081, China
}

\section{A R T I C L E I N F O}

\section{Article history:}

Received 12 April 2014

Received in revised form

31 July 2014

Accepted 19 August 2014

Available online 2 September 2014

\begin{abstract}
A B S T R A C T
Bovine lactoferrin (bLF) was shown to efficiently inhibit the growth of MCF-7, T-47D, MDA-MB-231 and Hs578T breast cancer cells in a concentration-dependent manner. However, apoptosis was only induced in MCF-7 cells, which was associated with the mitochondria membrane depolarisation and a decrease of Bcl-2 levels. bLF led to the cycle arrest of MCF-7 cells at G1/G0 phase, as well as a significant decrease in the expression of CDC25c. The possibility that the observed anticancer effects could be due to the high exogenous bLF concentrations in the culture media was excluded. Moreover, bLF was shown to restrain the colony formation of MCF-7 cells, although it promoted cell migration. This later effect was unspecific and related to the presence of a high protein concentration in the culture or medium. The results gathered in this work provide valuable insights for the evaluation and further study of the potential of bLF in cancer therapy.
\end{abstract}

() 2014 Elsevier Ltd. All rights reserved.

\section{Introduction}

Due to safety concerns on the use of pharmaceuticals, as well as their regulatory limitations, dietary agents are becoming attractive alternatives as cancer chemo-preventive agents (Korhonen \& Pihlanto, 2006; Wakabayashi, Yamauchi, \& Takase, 2006). Some dietary agents, such as selenium (Yamada et al., 2008), vitamin D and green tea polyphenols have been described as interesting chemo-preventive agents for prostate cancer (Syed, Khan, Afaq, \& Mukhtar, 2007).

Lactoferrin (LF), a milk-derived glycoprotein, is widely distributed in several secretion fluids of mammalian cells, being extremely abundant in milk (Kappeler, Ackermann, Farah, \& Puhan, 1999). This protein has been assigned with multiple biological functions, including antibacterial, antiviral, antifungal and immune regulatory activities (Adlerova, Bartoskova, \& Faldyna, 2008; Wakabayashi et al., 2006). Iron chelation by LF is generally believed to be responsible for these functions, especially for the antibacterial effect (Jenssen \& Hancock, 2009). More interestingly, it has been found that down-regulation of the LF gene could be

\footnotetext{
* Corresponding author. Tel.: +351 253604401.

E-mail addresses: 1rmr@deb.uminho.pt, 1rmr@mit.edu (L.R. Rodrigues).
}

associated with higher incidence of breast cancers (Furmanski, Li, Fortuna, Swamy, \& Das, 1989). On the other hand, the exogenous supply of LF and its variants were reported to efficiently inhibit the cancer growth both in vitro and in vivo (Damiens et al., 1999; Xu et al., 2010; Yamada et al., 2008).

Despite its great potential, the mechanisms underlying the LF and its variants cytotoxicity against cancer cells are still relatively unknown. The genetically-induced overexpression of human lactoferrin (hLF) in MCF-7 cells was reported to promote cellular apoptotic activities (Liao, Du, \& Lönnerdal, 2010). Also, recombination adenovirus-mediated hLF cDNA led to cell cycle arrest and stimulated apoptosis in MCF-7 cells associated with a decrease of Bcl-2 (Wang et al., 2012). Furthermore, the restoration of deltalactoferrin ( $\triangle$ LF) in HEK 293 cells resulted in cell cycle arrest and growth retardation (Breton et al., 2004). Importantly, exogenous hLF could efficiently inhibit in vitro the growth of cancer cells and induce cell cycle arrest at G1 phase (Yamada et al., 2008; Zhou et al., 2008). This effect occurred through a p53-independent pathway, and the key G1 regulatory proteins played an important role in the process (Yamada et al., 2008). Additionally, bovine lactoferrin (bLF) was found to induce apoptosis of SGC-7901 human stomach cancer cells by inhibiting the Akt activation and regulating its downstream signals (Xu et al., 2010). 
However, hLF-induced apoptosis in PC12 cells (rat pheochromocytoma cells) was observed to be associated with a decrease in the expression of the phosphorylated extracellular-signalregulated kinase $1 / 2$ (ERK1/2) and Bcl-2 (Lin, Chiou, Chen, \& Kuo, 2005). In addition, hLF was reported to induce apoptosis of Jurkat $\mathrm{T}$ cells via the regulation of c-Jun N-terminal kinase (JNK) activity (Lee et al., 2009). Furthermore, the main bLF-derived peptide, lactoferricin (LfcinB), also showed similar effects as its parent protein. Nevertheless, LfcinB inhibited the proliferation of cancer cells mainly by activating apoptosis-inducing pathways (Furlong, Mader, \& Hoskin, 2006; Onishi, Roy, Juneja, Watanabe, \& Tamai, 2008; Roy, Kuwabara, Hara, Watanabe, \& Tamai, 2002; Sakai, Banno, Kato, Nozawa, \& Kawaguchi, 2005). JNK/SAPK (stress-activated protein kinase) activation, down-regulation of $\mathrm{Bcl}-2$, mitochondria swelling and release of cytochrome $c$ were believed to be the mechanisms underlying the LfcinB cytotoxicity against cancer cells (Mader, Salsman, Conrad, \& Hoskin, 2005; Sakai et al., 2005).

All these in vitro reports suggest that the mechanisms behind LF and LfcinB cytotoxicity against cancer cells are greatly dependent on the cell type (Duarte, Nicolau, Teixeira, \& Rodrigues, 2011; Furlong et al., 2006; Lin et al., 2005; Xu et al., 2010). Additionally, the potential of LF for application in cancer therapy was further confirmed in vivo. In those experiments, the anticancer effect of LF was shown to be mainly exerted through activation of both the innate and adaptive immune responses, as well as through the stimulation of the proliferation and differentiation of T helper cells (Th) into type 1 helper cell (Th1) or type 2 helper cell (Th2) phenotypes, which release tumour-killing cytokines (tumour necrosis factors (TNF), interferon- $\gamma$ (IFN- $\gamma$ ), caspase-1 and interleukin-18 (IL-18)) in the intestine and tumour (De la Rosa, Yang, Tewary, Varadhachary, \& Oppenheim, 2008; Fischer, Debbabi, Dubarry, Boyaka, \& Tome, 2006; Kuhara, Yamauchi, \& Iwatsuki, 2012).

Considering the established correlation between LF and breast cancer, in the present work we studied the bLF cytotoxicity against several breast cancer cells and proposed the possible mechanisms involved in such anticancer effect. Evidence provided by the in vitro experiments will be of great value towards a future clinical use of bLF in chemoprevention and cancer therapy.

\section{Materials and methods}

\subsection{Cell lines and lactoferrin}

T-47D and MDA-MB-231 breast cancer cell lines were kindly provided by IPATIMUP and Medical School of University of Porto (Portugal), respectively. Hs578T cells were donated by the Life and Health Sciences Research Institute, University of Minho (Portugal). MCF-7 was bought from the American Type Culture Collection. The cells were cultured at $37{ }^{\circ} \mathrm{C}$ in a humidified incubator with a $5 \% \mathrm{CO}_{2}$ atmosphere in L-glutamine-containing DMEM medium (Biochrom AG, Berlin, Germany) supplemented with $10 \%$ foetal bovine serum (FBS) (Biochrom AG) and $100 \mathrm{U} \mathrm{mL}^{-1}$ penicillin/streptomycin (Sigma-Aldrich, Steinheim, Germany). Bovine lactoferrin was purchased from DMV (Veghel, The Netherlands). The protein purity is about $80 \%$ with $3.5 \%$ moisture and $21 \%$ iron-saturated according to the manufacturer.

\subsection{Effects on cell growth and death}

Trypan blue staining was used to estimate cell growth and cell death induced by the bLF treatment. Breast cancer cells (MCF-7, T47D, MDA-MB-231 and Hs578T) were seeded in 24-well plates overnight. Afterwards, bLF at several concentrations $(12.5 \mu \mathrm{M}$, $50 \mu \mathrm{M}, 125 \mu \mathrm{m}$ and $175 \mu \mathrm{m}$ ) was added to each well. After a $48 \mathrm{~h}$ of treatment, both floating and attached cells were collected and resuspended in medium to obtain an adequate cell concentration. A $50 \mu \mathrm{L}$ volume of suspended cells were mixed with $50 \mu \mathrm{L}$ of trypan blue $0.04 \%(\mathrm{w} / \mathrm{v})$ (Sigma-Aldrich) and were incubated for $5 \mathrm{~min}$ before counting viable and non-viable cells using a haemocytometer under a light microscope. The cells able to exclude trypan blue (viable cells) and stained in blue (dead cells) were used to estimate cell growth. The control (without bLF treatment) was set as $100 \%$. Cell viability was expressed in percentage and calculated according to the following equation: Number of viable cells/total number of cells $\times 100$.

\subsection{Nuclear condensation assay}

The ability of bLF to induce cell death by apoptosis was estimated by the nuclear condensation assay as previously described (Dias, Duarte, Lima, Proença, \& Pereira-Wilson, 2013). In brief, cells at exponential phase were collected and seeded in 6-well plates. After $24 \mathrm{~h}$ of incubation, the cells were treated for $72 \mathrm{~h}$ with bLF at several concentrations $(12.5 \mu \mathrm{M}, 50 \mu \mathrm{M}, 125 \mu \mathrm{M}$ and $175 \mu \mathrm{M})$. Then, both floating and attached cells were collected, fixed and attached to a polylysine-treated slide using a Shandon Cytospin 4 (Thermo Scientific, Waltham, MA, USA). Nuclei were stained with Hoechst $\left(5 \mu \mathrm{g} \mathrm{mL} \mathrm{m}^{-1}\right)$ fluorescent dye for $10 \mathrm{~min}$ in the dark and observed under a fluorescent microscope (Olympus IX71, Hamburg, Germany). The apoptosis rate was calculated as the number of cells presenting nuclear condensation divided by the total number of cells (stained in blue) from a count higher than 400 cells per slide.

\subsection{Annexin V/propidium iodide (PI) staining}

Annexin V/PI staining was also used to estimate cell death by apoptosis. MCF-7 cells were seeded in 6-well plates for $24 \mathrm{~h}$. Subsequently, cells were treated with $12.5 \mu \mathrm{m}, 50 \mu \mathrm{m}, 125 \mu \mathrm{m}$ and $175 \mu \mathrm{m}$ of bLF. After $48 \mathrm{~h}$ of bLF treatment, the cells were collected and washed twice with ice-cold PBS and resuspended in $1 \times$ Binding Buffer (0.01 м Hepes, pH 7.4, 0.14 м NaCl, $2.5 \mathrm{M} \mathrm{CaCl}_{2}$ ) to get a final cell concentration of $1 \times 10^{6}$ cells $\mathrm{mL}^{-1}$. A $100 \mu \mathrm{L}$ volume of each sample was then stained with $5 \mu$ L FITC Annexin V (BD Pharmingen, Franklin Lakes, NJ, USA) and $10 \mu \mathrm{L}$ PI $\left(50 \mu \mathrm{g} \mathrm{mL}^{-1}\right)$. After a $15 \mathrm{~min}$ incubation at room temperature, cells were then analysed by flow cytometry using a Coulter Epics XL flow cytometer (Beckman Coulter Inc., Miami, FL, USA).

\subsection{Cell cycle analysis}

MCF-7 cells were seeded on $100 \mathrm{~mm}$ petri dish and cultured for $24 \mathrm{~h}$. Fresh medium with $12.5 \mu \mathrm{m}, 50 \mu \mathrm{M}, 125 \mu \mathrm{m}$ and $175 \mu \mathrm{m}$ of bLF was added to the cells and incubated for $24 \mathrm{~h}$. In the end, the cells were collected and processed for cell cycle analysis as previously described (Dias at al., 2013).

\subsection{Mitochondrial membrane potential assay}

MCF-7 cells were incubated with different concentrations of bLF $(12.5 \mu \mathrm{m}, 50 \mu \mathrm{M}, 125 \mu \mathrm{m}$ and $175 \mu \mathrm{m})$ for $2 \mathrm{~h}, 24 \mathrm{~h}$ and $48 \mathrm{~h}$. A positive control was included, containing carbonyl cyanide 3chlorophenylhydrazone (CCCP, Sigma-Aldrich) at a $50 \mu \mathrm{m}$ and incubated for $30 \mathrm{~min}$ at $37^{\circ} \mathrm{C}$ before cell collection. Subsequently, cells were resuspended in $1 \mathrm{~mL}$ of warm-PBS, and $10 \mu \mathrm{L}$ of $200 \mu \mathrm{m}$ JC-1 (Molecular Probes, Life Technologies, Eugene, OR, USA) was added to each sample and incubated for 15 min under cell culture conditions. At last, the samples were analysed by flow cytometry (Beckman Coulter Inc.). 


\subsection{Histone extraction}

MCF-7 cells were incubated with $12.5 \mu \mathrm{m}$ and $125 \mu \mathrm{m}$ bLF for $1 \mathrm{~h}$, $6 \mathrm{~h}$ and $12 \mathrm{~h}$. Incubation of cells with $50 \mu \mathrm{m}$ etoposide was used as positive control for DNA damage. Cells were collected and washed with ice-cold PBS. Next, cells were resuspended in Triton Extraction Buffer (TEB: PBS with $0.5 \%$ Triton X-100 (v/v), 2 mm phenylmethylsulfonyl fluoride, $\left.0.02 \%(\mathrm{w} / \mathrm{v}) \mathrm{NaN}_{3}\right)$ at a cell density of $1 \times 10^{7}$ cells $\mathrm{mL}^{-1}$. The cell suspension was left on ice for $10 \mathrm{~min}$ with gentle stirring; nuclei were centrifuged at $6500 \times \mathrm{g}$ for $10 \mathrm{~min}$ at $4{ }^{\circ} \mathrm{C}$ and washed once with half volume of TEB. Subsequently, the nuclei pellet was resuspended in $0.2 \mathrm{~N} \mathrm{HCl}$ at a density of $4 \times 10^{7}$ nuclei $\mathrm{mL}^{-1}$ to perform an acid extraction of histones overnight at $4{ }^{\circ} \mathrm{C}$. After centrifugation, the supernatant containing histone protein was used for further analysis. The histone protein extracts were quantified using the Bradford reagent from Sigma-Aldrich and analysed by western blot. The antibody against phosphohistone H2A.X (Ser139, clone JBW301) was bought from Millipore, while anti- $\beta$-actin was from Sigma-Aldrich.

\subsection{Western blot assay}

MCF-7 cells were seeded in 6-well pates $24 \mathrm{~h}$ before incubating cells with bLF at the concentrations of $12.5 \mu \mathrm{M}, 50 \mu \mathrm{M}, 125 \mu \mathrm{m}$ and $175 \mu \mathrm{m}$ for $48 \mathrm{~h}$. After cell washing with PBS, total protein was extracted using RIPA (Radio-Immunoprecipitation Assay) buffer. Protein from the samples were loaded onto a 10\% SDS-PAGE gel and transferred into PVDF membranes (GE Healthcare, Buckinghamshire, UK). Immunoreactive bands were detected using the Immobilon solutions (Millipore, Billerica, MA, USA) under a chemiluminescence detection system, the ChemiDoc XRS (Bio-Rad Laboratories, Inc.). Band area intensity was quantified using the Quantity One software from Bio-Rad. $\beta$-Actin was used as loading control. The antibodies anti-CDC25c, anti-Bcl-2 and anti-p53 were acquired from Santa Cruz Biotechnology (Santa Cruz, CA, USA).

\subsection{Colony formation assay}

MCF-7 cells were trypsinised and pipetted repeatedly to disperse them until single cells account for $95 \%$ of the total number of cells. Next, the cells were counted and then seeded in 6-wellplates to a concentration of $1 \times 10^{3}$ cells per well and incubated for 24 h. Subsequently, the cells were treated with bLF at several concentrations ( $12.5 \mu \mathrm{M}, 50 \mu \mathrm{M}, 125 \mu \mathrm{m}$ and $175 \mu \mathrm{m})$, while DMEM without FBS was used as a positive control. After $24 \mathrm{~h}$ incubation with bLF, the media in all wells was replaced with fresh media (DMEM with 10\% FBS). After 7-10 days, the cells were fixed with $70 \%$ methanol for $15 \mathrm{~min}$ and air dried. Giemsa was used to stain cells for $10 \mathrm{~min}$ and was subsequently washed carefully with water. Colonies containing at least 50 cells were counted. Colony formation was calculated as the ratio between the number of colonies in the experimental samples and the number of colonies in the control sample.

\subsection{Migration assay}

The bottom of 6-well plates was marked with 5-10 straight lines with $0.2 \mathrm{~cm}$ interval among the lines. Subsequently, $5 \times 10^{5}$ MCF-7 cells per well were seeded in 6-well plates for growing until cell confluence reached over $85 \%$. Then, a scratch wound across each well of the 6 -well plates was made using a pipette tip. Next, cells were washed twice with PBS and FBS-free DMEM containing $175 \mu \mathrm{m}$ bLF or BSA was added. Cells were photographed at the exact same point (marked with straight line) in the 6 -well plates after $0 \mathrm{~h}$, $6 \mathrm{~h}, 12 \mathrm{~h}$ and $24 \mathrm{~h}$. The cell migration ratio was calculated by comparing the wound area at the different time points with the wound area at $0 \mathrm{~h}$ in each group.

\subsection{Statistical analysis}

Statistical significance of the experimental results was determined by the Student's $t$ test. For p-values below 0.05 the differences between experimental groups were considered significant.

\section{Results}

\subsection{Lactoferrin inhibits the growth of breast cancer cells}

To test whether bLF was able to inhibit the growth of the breast cancer cells, the trypan blue staining method was firstly used since it provides information on growth inhibitory activities and total cell death. Considering the total number of cells in each well, we observed that bLF significantly inhibited the growth of breast cancer cells after $48 \mathrm{~h}$ of treatment in a concentration-dependent manner (Fig. 1). The magnitude of growth inhibition was identical in all cell lines, which indicates that this effect is not cell type specific. Cell growth inhibition reached about $70 \%-80 \%$ for an exposure to $175 \mu \mathrm{m}$ bLF. For these conditions, in the case of the Hs578T cell line, cell death increased about $30 \%$ as compared with non-treated cells. However, few dead cells were observed in the experiments conducted with the other cell lines (data not shown). These results suggest that the inhibitory effect of bLF is mostly associated with the inhibition of cell proliferation.

\subsection{Lactoferrin selectively induces apoptosis in MCF-7 cells}

Based on the observation that some cell death occurred in the experiments with Hs578T cells, we then performed a nuclear condensation assay to estimate the potential induction of apoptosis. However, at $48 \mathrm{~h}$ no evident nuclear condensation could be observed in any of the cell lines used (data not shown), which corroborates the lack of massive cell death shown above. Regarding this phenomenon, we hypothesise that the cell death by apoptosis could be a more delayed event. Therefore, induction of apoptosis was evaluated $72 \mathrm{~h}$ after incubation of cells with bLF. The results demonstrated that bLF failed to induce apoptosis in all breast cancer cell lines under study (data not shown), except for the MCF7 cells (Fig. 2). Cells presenting nuclear condensation are shown with arrows in Fig. 2A. Nuclear condensation was found to increase in a dose-dependent way in MCF-7 cells, reaching a ratio of about $35 \%$ after $72 \mathrm{~h}$ of treatment with $175 \mu \mathrm{m}$ bLF (Fig. 2B). This assay indicated that bLF could selectively induce apoptosis in MCF-7 cells among the tested breast cancer cells.

To confirm the induction of apoptosis by bLF in the MCF-7 cells, the annexin V/PI assay was performed after $40 \mathrm{~h}$ of incubation, since the translocation of phosphatidylserine for the outer leaflet of plasma membrane is an apoptotic event that occurs earlier than the DNA fragmentation (Elmore, 2007). The results showed that the amount of non-apoptotic cells (Q4 region: annexin $\mathrm{V}$ negative/PI negative) decreased in a concentration-dependent manner compared to the non-treated group (Fig. 2C). In contrast the number of cells in the early stage $(\mathrm{Q} 3$ region: annexin $\mathrm{V}$ positive/PI negative) and later stage of apoptosis ( $\mathrm{Q} 2$ region: annexin $\mathrm{V}$ positive/PI positive) was considerably increased by bLF in a concentration-dependent manner. Although the percentage of apoptotic cells in bLF-treated groups estimated by the Annexin V/PI assay was less than the one determined by the nuclear condensation assay, it was possible to confirm the ability of bLF to induce apoptosis in MCF-7 cells. 
MCF.7
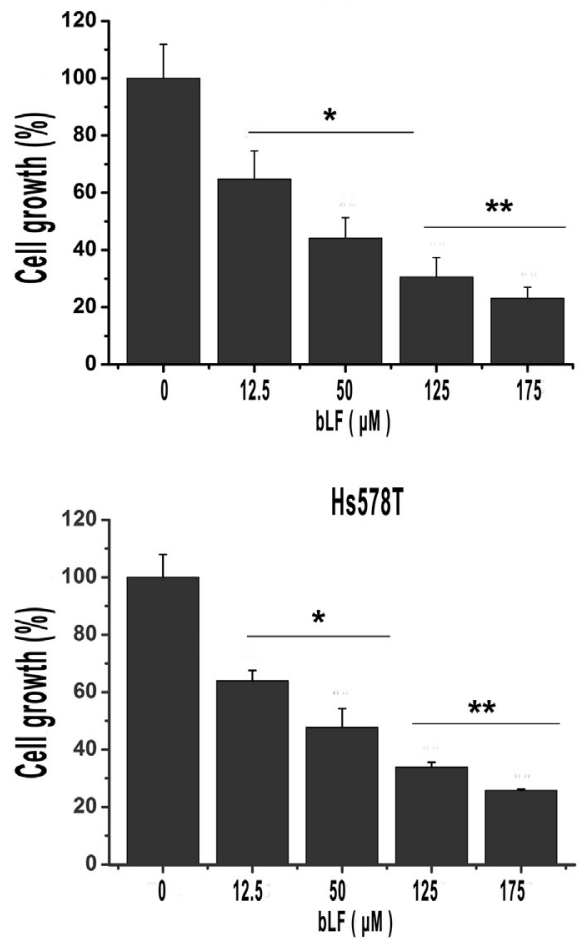

T-47D
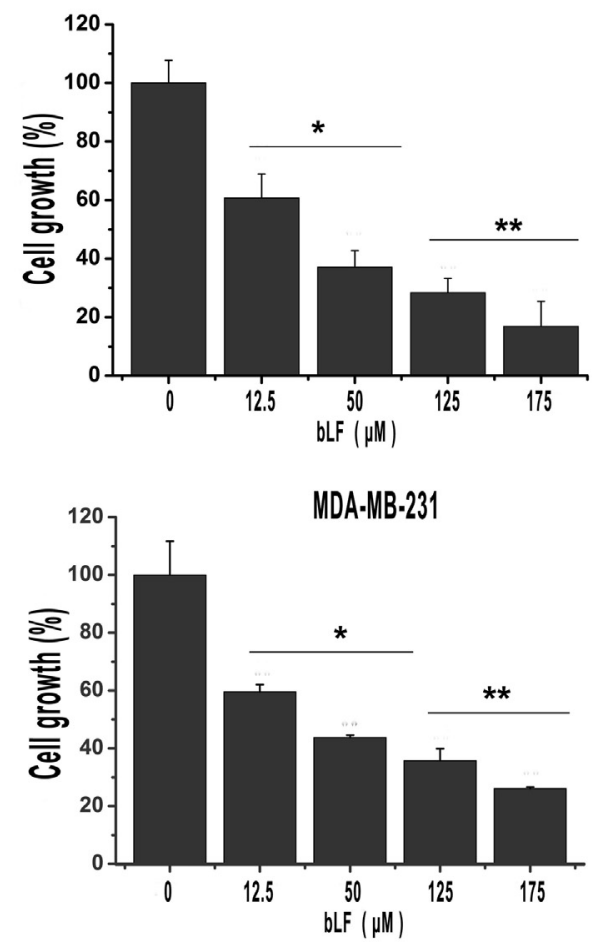

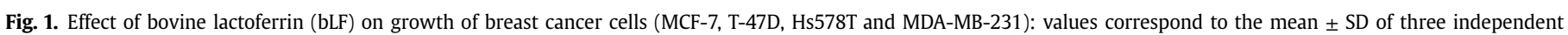
experiments; ${ }^{*} p<0.05$ and ${ }^{* *} p<0.01$ when compared with the control.

\subsection{Lactoferrin inhibits cell cycle progression in MCF-7 cells}

Considering that apoptotic cell death was only observed in MCF7 cells, in this experiment we only tested this cell line to infer the effects of bLF in the cell cycle progression. As shown in Fig. 3A, bLF clearly induced cell cycle arrest of MCF-7 cells at the G1 phase after $24 \mathrm{~h}$ of treatment, and this effect increased in a dose-dependent manner. This event was accompanied with a remarkable decrease in the percentage of cells at the $S$ phase (cells synthesising DNA).

Since the concentration of bLF being used was relatively high $(175 \mu \mathrm{M})$, reaching a quantity of $14 \mathrm{~g} \mathrm{~L}^{-1}$ in the culture media, we questioned whether the observed effects could be due to this considerable amount of exogenous protein added, which would disturb the cellular microenvironment and prevent cell division. Therefore, a parallel assay using bLF and bovine serum albumin (BSA) at similar amounts (14 $\mathrm{g} \mathrm{L}^{-1}$ ) on the MCF-7 cell cycle progression was conducted. As shown in Fig. 3A, BSA also induced cell cycle arrest of MCF-7 cells at the G1 phase. However, this effect was found to be much lower when compared to bLF. Moreover, cells incubated with bLF presented a distinct morphology, while the morphology of the BSA treated group was very similar to the control one (Fig. 3B). This suggests that bLF could significantly inhibit the MCF-7 cell growth through cell cycle arrest due to a specific biological function.

DNA damage is one of the main events that lead to cell cycle arrest. Since it was shown that cells can internalise bLF, it is plausible to consider that bLF may arrest the cell cycle by inducing DNA damage. A very early step in the cellular response to DNA doublestrand breaks (DSBs) is the phosphorylation of a histone $\mathrm{H} 2 \mathrm{~A}$ variant, H2A.X, at the sites of DNA damage. Therefore, the phosphorylation levels of histone H2A.X was used as a marker of DNA damage. As shown in Fig. 3C, the exposure of MCF-7 cells to $12.5 \mu \mathrm{m}$ and $125 \mu \mathrm{M}$ bLF did not induce phosphorylaton of histone H2A.X, contrarily to the positive control etoposide $(50 \mu \mathrm{m})$. Therefore, these results demonstrate that the induction of cell cycle arrest by bLF was not due to DNA double-strand breaks.

\subsection{Lactoferrin decreases mitochondrial membrane potential}

In the apoptotic cascade, mitochondrial depolarisation is usually associated to the intrinsic apoptosis pathway (Ly, Grubb, \& Lawen, 2003). In this study, we used the JC-1 probe to assess the modification of the mitochondrial membrane potential in MCF-7 cells after treatment with bLF for $2 \mathrm{~h}, 24 \mathrm{~h}$ and $48 \mathrm{~h}$. After $2 \mathrm{~h}$ of bLF treatment at several concentrations $(12.5 \mu \mathrm{m}, 50 \mu \mathrm{M}, 125 \mu \mathrm{m}$ and $175 \mu \mathrm{M}$ ), it could be observed a significant decrease of the red to green ratio in the fluorescence, which represents the decrease of the mitochondrial membrane potential. Furthermore, the depolarisation effects of bLF on mitochondria increased in a dose-dependent way (Fig. 4A). The mitochondrial depolarisation occurred in all bLF-treated groups after $24 \mathrm{~h}$ incubation, although not in a dosedependent manner. Contrarily, after 48 h of bLF treatment, mitochondria depolarisation was found to be more pronounced and to be dependent on the bLF concentration. From the cell distribution in the dot plot graph, it was observed that treatment of MCF-7 cells with $175 \mu \mathrm{m}$ bLF for $48 \mathrm{~h}$ led to a significant shift of the number of cells with red to green fluorescence, as compared with the nontreated cells ( $0 \mu \mathrm{m}$ bLF) (Fig. 4B). In fact, the percentage of cells with depolarised mitochondria after $48 \mathrm{~h}$ of bLF treatment (30\%) is similar to the apoptosis rate observed at $72 \mathrm{~h}$ (35\%). When cells were observed under a fluorescent microscope it was confirmed that bLF induced the depolarisation of mitochondria in a significant part of the cell population, in contrast to the positive control CCCP that basically depolarised the mitochondria of all cells. As a control condition for protein load, $175 \mu \mathrm{M}$ BSA treatment for $48 \mathrm{~h}$ was also tested, but no significant differences from the control were observed (data not shown). This shows that bLF-induced mitochondria depolarisation is a specific effect of this protein. 
A

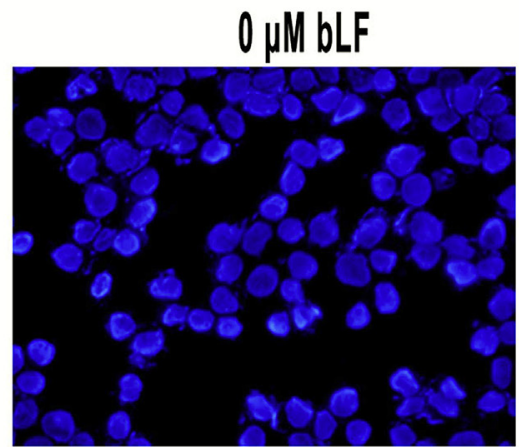

$50 \mu M$ bLF

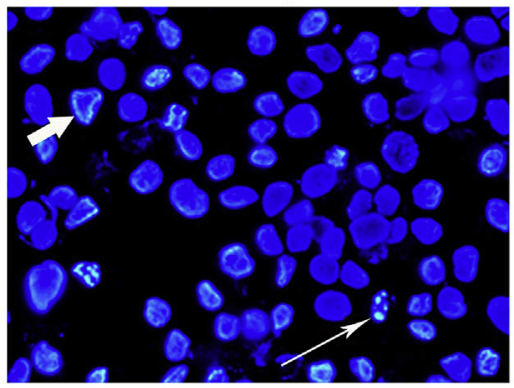

$125 \mu \mathrm{M} \mathrm{bLF}$

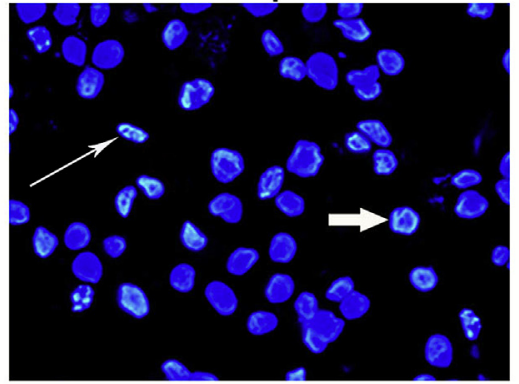

$12.5 \mu M \mathrm{bLF}$

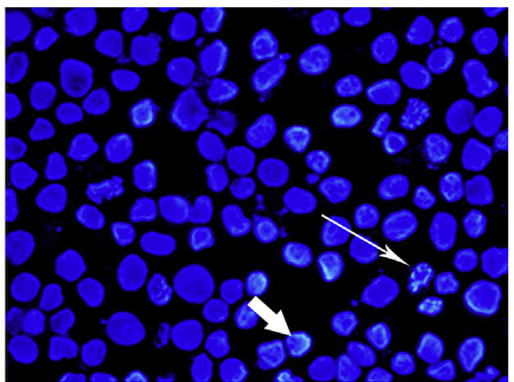

C

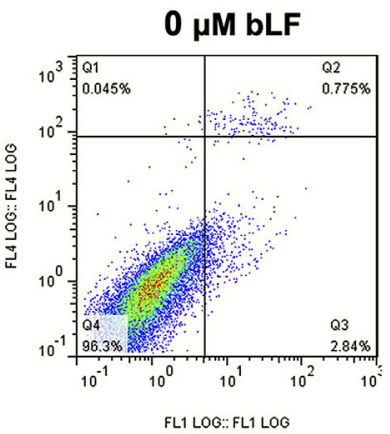

$125 \mu \mathrm{M}$ bLF

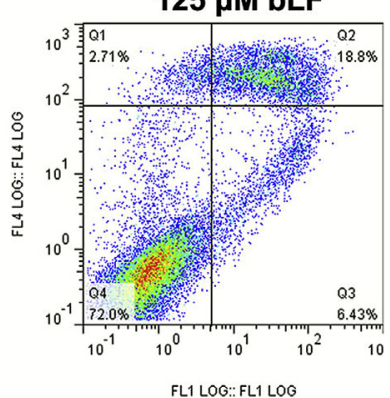

FL1 LOG:: FL1 LOG
$175 \mu M b L F$

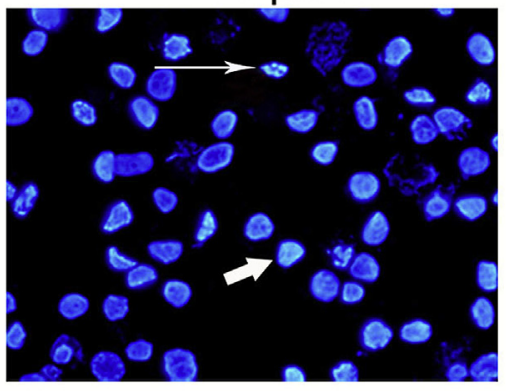

B

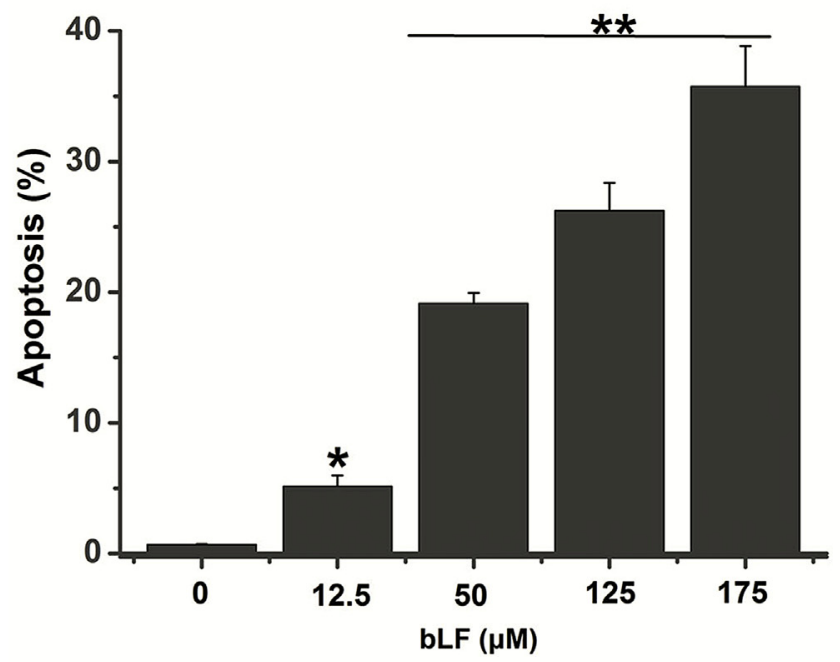

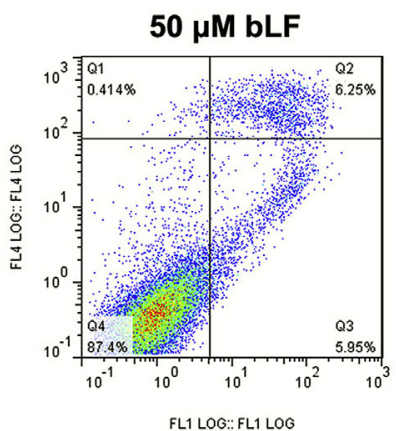

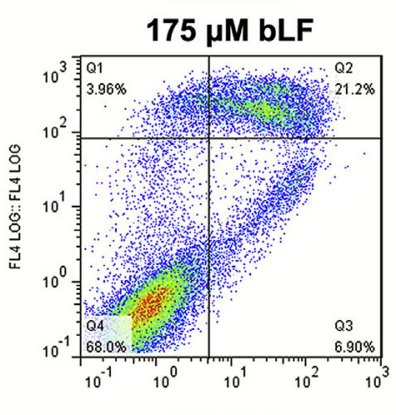

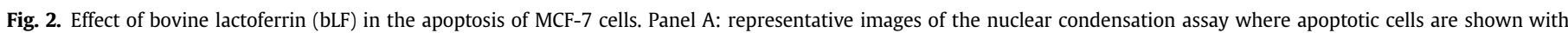

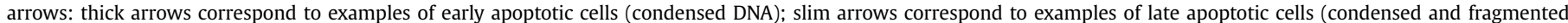

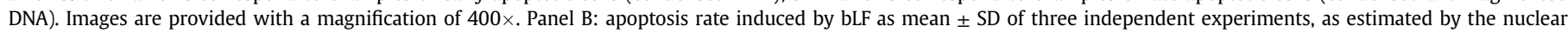

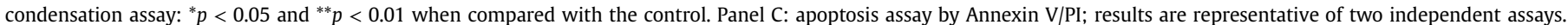

\subsection{Downregulation of Bcl-2 was associated with the lactoferrin- induced apoptosis}

Considering the apoptosis and mitochondria membrane depolarisation observed in MCF-7 cells treated with bLF, the expression of Bcl-2 was also studied by western blot. As shown in Fig. 5A, bLF significantly decreased in a concentration-dependent manner the expression of the anti-apoptotic protein $\mathrm{Bcl}-2$. Moreover, it is known that the tumour suppressor gene p53 has a critical role in the regulation of $\mathrm{Bcl}-2$ and other proteins of the $\mathrm{Bcl}-2$ family (Meulmeester \& Jochemsen, 2008). However, by western blot analysis we did not observe significant changes in the total levels of p53 in the bLF-treated groups after $48 \mathrm{~h}$ of treatment (Fig. 5A).

Related with inhibition of cell proliferation, the levels of CDC25c were measured by western blot and shown to clearly decrease after bLF treatment for $48 \mathrm{~h}$ (Fig. 5A). Although it is not a key regulator in 
A

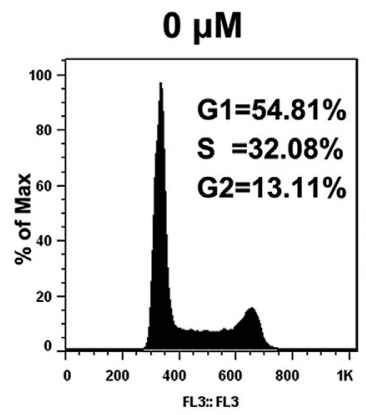

$12.5 \mu \mathrm{M}$ bLF

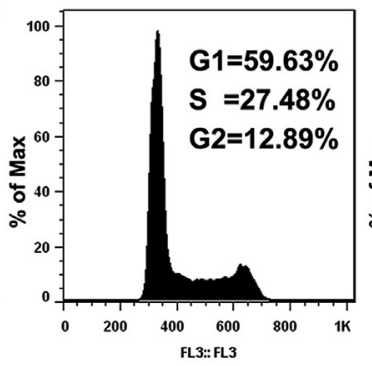

$0 \mathrm{~g} / \mathrm{L}$
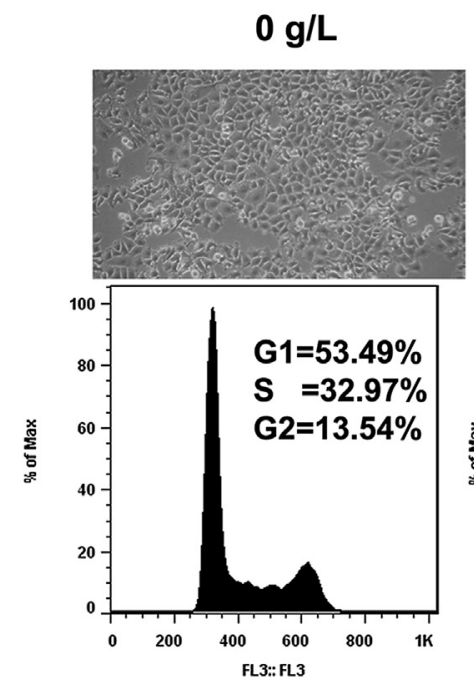

$50 \mu \mathrm{M} \mathrm{bLF}$

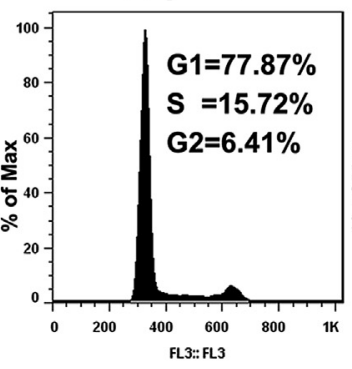

$14 \mathrm{~g} / \mathrm{L}$ BSA
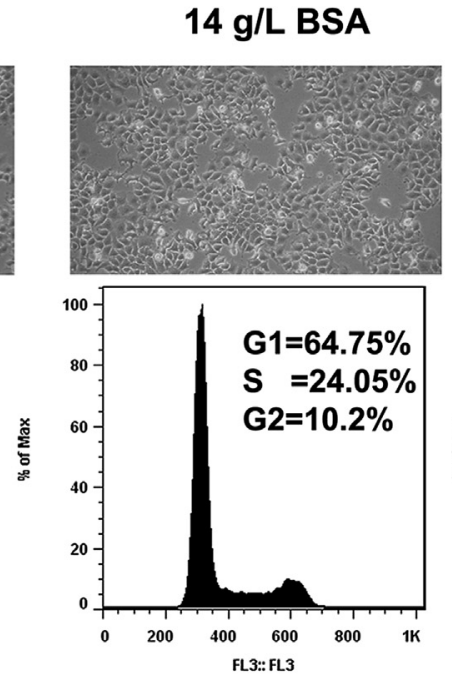

$125 \mu \mathrm{M}$ bLF
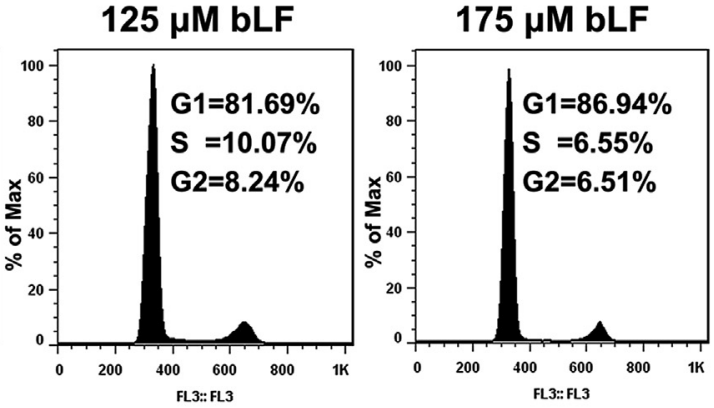

B

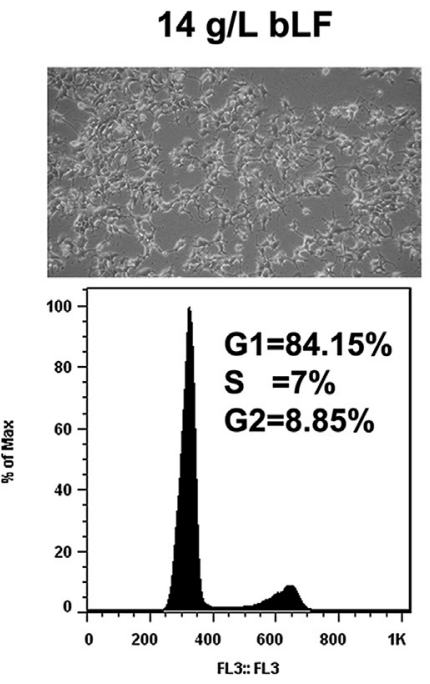

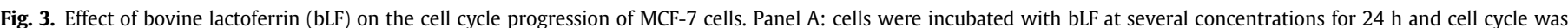

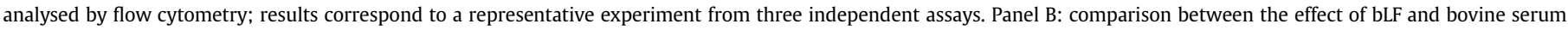

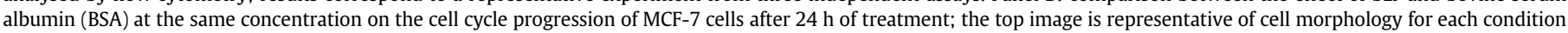
(magnification of the images: $40 \times$ ).

the G1/S transition of cell cycle, the downregulation of CDC25c suggests that bLF induced cell cycle arrest through the regulation of key factors in the cell cycle progression.

\subsection{Lactoferrin significantly inhibits colony formation}

Considering that bLF inhibited cell growth of MCF-7 cells due to both cell cycle arrest and induction of apoptosis, we then performed an anchorage-dependent colony formation assay as a functional assay to determine the effectiveness of the bLF anticancer effect. This assay essentially tests the ability of a single cell to grow into a colony by undergoing cell division. By comparing with the control condition ( $0 \mu \mathrm{m}$ bLF), the bLF-treated cells exhibited a much lower cloning efficiency (Fig. 5B and C). The number of colonies in the treatment with $175 \mu \mathrm{m}$ bLF could only reach $2.6 \%$ of the control $\left({ }^{* * *} p<0.001\right)$. Additionally, DMEM media without FBS used as a positive control also inhibited the colony formation.

\subsection{Induction of cell migration by bovine lactoferrin in MCF-7 cells is not specific of this protein}

Metastasis is the primary cause of mortality in most cancer patients. The repression of the metastatic process has been used as an important strategy in cancer therapy. Cell migration and invasion are the two key factors involved in the metastasis formation (Valster et al., 2005). LF was previously described as a promoting factor for the migration of MCF-7 cells (Ha et al., 2011). Herein, we also tested the effect of bLF in cell migration, and we indeed observed that this protein promotes the migration of MCF-7 cells at $175 \mu \mathrm{m}$ (Fig. 6). To test if this effect was only due to the presence of a higher concentration of protein in the extracellular milieu, we also compared the results with an experiment conducted with the same concentration of another protein, namely BSA. Cell migration was greatly increased when cells were treated with BSA. Actually, BSA appeared to be more efficient in promoting cell migration than the bLF after $6 \mathrm{~h}$ of treatment. However, no significant differences were found between BSA- and bLF-treated groups after $12 \mathrm{~h}$ and $24 \mathrm{~h}$ of incubation. This result showed that the ability of bLF to induce cell migration is an unspecific property and it may result from a positive change of cell microenvironment due to the presence of a high concentration of exogenous protein.

\section{Discussion}

In this study, we demonstrated that bLF at several concentrations significantly inhibited the growth of the four breast cancer cell lines, but it induced apoptosis only in MCF-7 cells. The different genetic profiles among the used cells may explain this selectivity in the apoptosis induction. For example, the p53 gene that plays an important role in this type of cell death (Meulmeester \& Jochemsen, 2008) may be associated with the present finding. Whereas T-47D, MDA-MB-231 and Hs578T cells harbour a mutated 
A

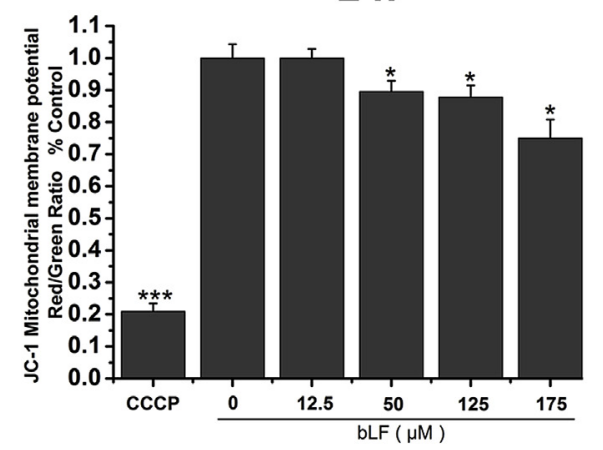

B
$2 \mathrm{~h}$

$0 \mu \mathrm{M}$
$24 \mathrm{~h}$

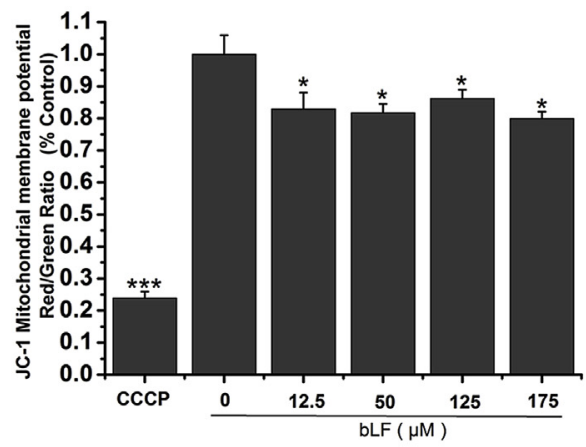

$48 \mathrm{~h}$

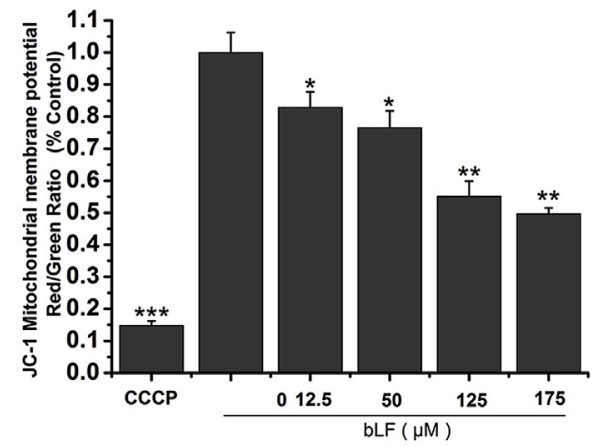

$175 \mu \mathrm{M}$ bLF

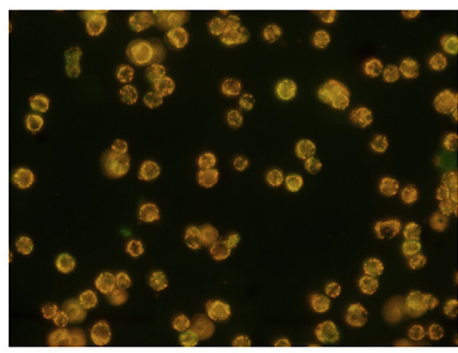

$50 \mu \mathrm{M} \mathrm{CCCP}$
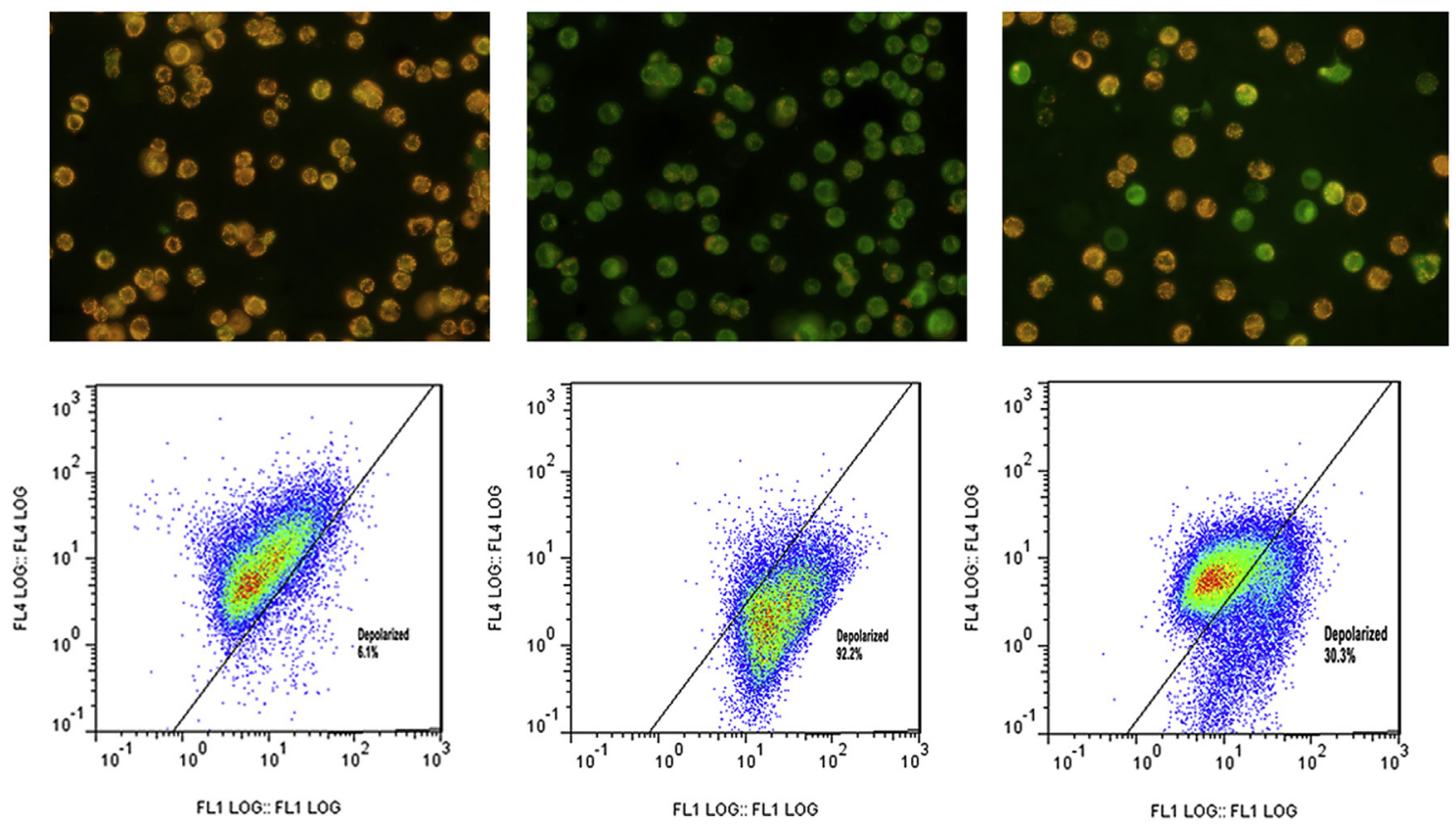

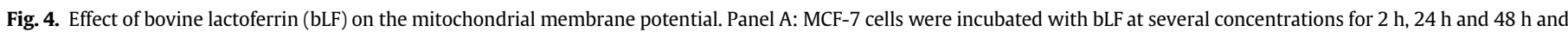

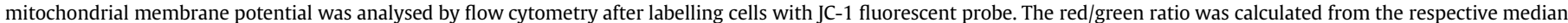

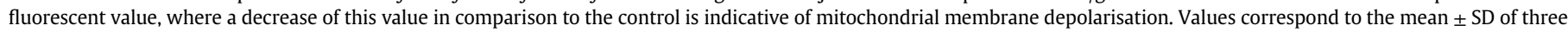

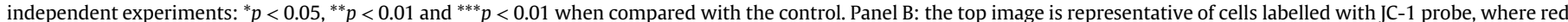

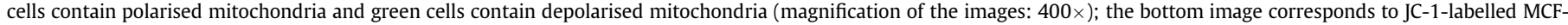

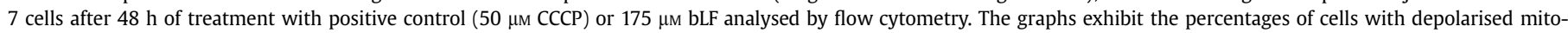
chondria (green positive/red negative). (For interpretation of the references to colour in this figure legend, the reader is referred to the web version of this article.)

p53 gene, MCF-7 cells possess a wild-type p53 (Jänicke, 2009; Xu et al., 2007). Therefore, the resistance of T-47D, MDA-MB-231 and Hs578T cells to undergo apoptosis in the presence of bLF may be due to the lack of the normal functions of $\mathrm{p} 53$. Previous studies reported the ability of LF to induce apoptosis in cancer cells (Damiens et al., 1999; Wang et al., 2011; Xu et al., 2010). The current study shows that this effect may depend on the genetic background of the cell line used, such as the presence of a functional p53 protein. Previously, we have reported the ability of bLF to inhibit cell growth of T-47D and Hs578T cells, and to increase the activity of caspases by 2 -fold as a marker of apoptosis (Duarte et al., 2011). However, as demonstrated here, this mild induction of caspases activity might not be enough to trigger cell death by apoptosis. Herein, we showed that bLF at higher concentrations induced selectively apoptosis in MCF-7 after $72 \mathrm{~h}$ of treatment.

Additionally, the bLF inhibitory effect on the MCF-7 cells growth was also shown to be associated with the cell cycle arrest at the G1 phase and a decrease of $\mathrm{CDC} 25 \mathrm{c}$ levels. This activity has been confirmed for hLF in some studies (Damiens et al., 1999; Wang et al., 2011). Regarding to MCF-7 cells, previous studies also demonstrated that re-expression of LF or $\Delta$ LF using several delivery vectors induced cell cycle arrest (Breton et al., 2004; Mader et al., 2005). In the current study we demonstrated that exogenous bLF could also induce cell cycle arrest in these cells. We also excluded that these anticancer effects triggered by bLF could be due to DNA damage.

Furthermore, the mitochondrial intrinsic death pathway has been reported as the main mechanism of LfcinB-induced apoptosis (Bi et al., 1996; Eliassen et al., 2006). Our results demonstrated that mitochondrial depolarisation was also associated in the bLFinduced apoptosis. This effect was also specific to bLF since no mitochondria depolarisation was observed when cells were treated with BSA. Depolarisation of the mitochondria membranes was kept during the time period ranging from $2 \mathrm{~h}$ to $48 \mathrm{~h}$, and no reversible 


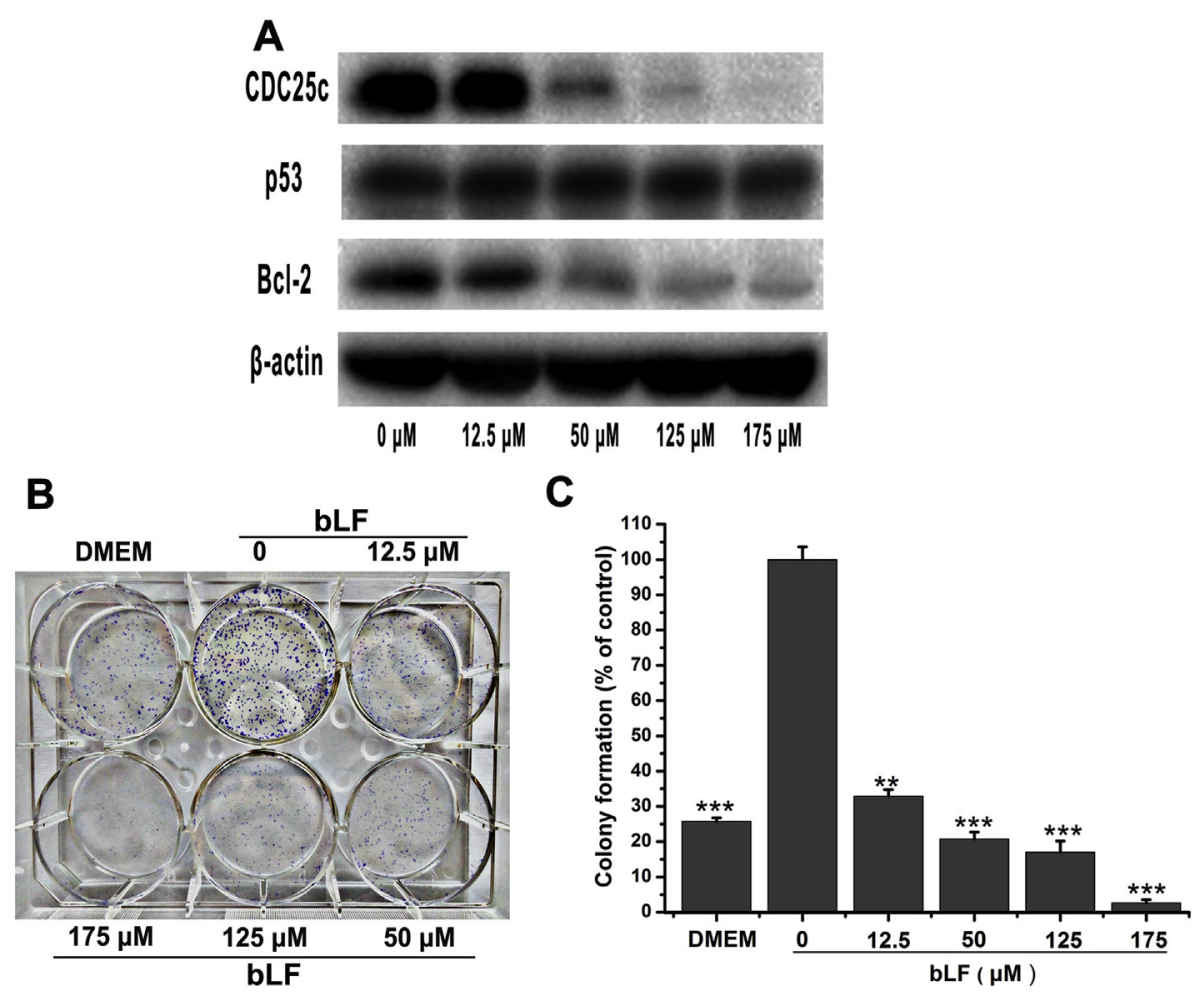

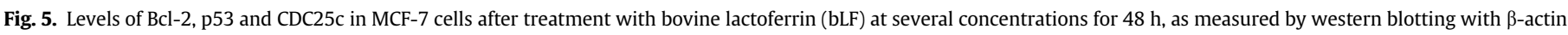

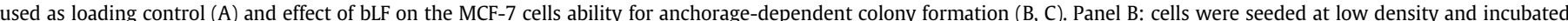

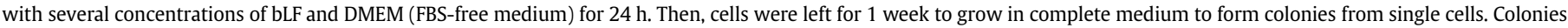

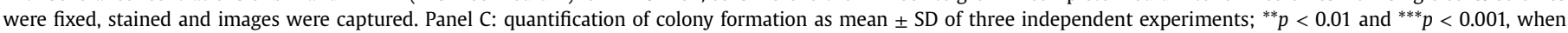
compared with the control $(0 \mu \mathrm{m}$ bLF).

change could be observed. The changes in the membrane potential presumably stand for the opening of the mitochondrial permeability transition (MPT) pore, which allows the release of cytochrome $\mathrm{c}$ from the mitochondria. This is a key event in the initiation of apoptosis cascade (Gottlieb, Armour, Harris, \& Thompson, 2003). Therefore, these findings suggest that depolarisation of mitochondria membrane potential is an important factor in the bLFinduced apoptosis of MCF-7 cells.

In addition to the mitochondrial depolarisation, bLF significantly decreased the anti-apoptotic Bcl-2 protein, which confirms that the intrinsic death pathway may be involved in the apoptosis induced by this protein. This is in a good agreement with former studies in other cancer cell lines that report LF- and LfcinB-induced apoptosis associated with a down-regulation of Bcl-2 (Mader et al., 2005; Wang et al., 2012; Xu et al., 2010). The decrease of Bcl-2 is considered as an important event to the opening of the MPT pore and loss of the mitochondrial membrane potential, for the release of cytochrome $c$ and other pro-apoptotic proteins characteristic of the intrinsic apoptosis pathway (Lin et al., 2005). It is known that the tumour suppressor gene $\mathrm{p} 53$ has a critical role in the regulation of Bcl-2 and other proteins of the Bcl-2 family (Kuhara et al., 2012). As we previously discussed, the p53 has probably a key role in the apoptosis selectively induced in MCF-7 cells as compared with the other used breast cancer cells. Although we did not find changes in the total p53 levels, this does not exclude that p53 may have an important function in the bLF-induction of apoptosis in MCF-7 cells, for example through its phosphorylation. However, a previous study with hLF showed that induction of apoptosis in cancer cells occurred through a p53-independent mechanism (Adlerova et al., 2008). The role of p53 in the apoptosis induction by bLF needs therefore to be further elucidated.
Finally, the bLF anticancer potential against MCF-7 cells was confirmed by its pronounced ability to inhibit the colony formation. These findings are in accordance with other reports. For instance, the hLF was previously shown to significantly inhibit the colony formation of nasopharyngeal carcinoma cells (Gottlieb et al., 2003). The efficient inhibition the colony formation of MCF-7 cells by bLF suggests its potential antitumour effect in vivo. Although bLF promoted the migration of MCF-7 cells, this effect was shown to be an unspecific effect of this protein. Therefore, this is probably not relevant in the in vivo context in view of the high concentration of proteins present in the biological fluids.

Interestingly, several studies have shown that bLF exhibits similar biological activities to hLF (Liao, Jiang, \& Lonnerdal, 2012; Lonnerdal, Jiang, \& Du, 2011). Although other LF sources could also be considered (e.g., camel, sheep or goat; Rodrigues, 2013), these have not been widely evaluated for their anti-cancer potential. Also, the mechanism by which bLF exerts its effect against MCF-7 cells in this study was found to be similar to the one reported for hLF (Adlerova et al., 2008; Fischer et al., 2006; Yamada et al., 2008). Therefore, bLF could be considered as a suitable substitute for hLF with the advantage that it can be produced in great amounts from bovine milk. On the other hand, the oral administration of bLF has been suggested as a good choice for chemoprevention strategies (Kuhara et al., 2000; Norrby, Mattsby-Baltzer, Innocenti, \& Tuneberg, 2001). New nanoparticles with bLF encapsulated have been developed for possible applications in the food and biopharmaceutical industries (Balcão et al., 2013; Hu et al., 2011). Additionally, the absence of adverse effects of bLF for humans at the proposed levels of consumption has been approved by European Food Safety Authority (EFSA). Therefore, we anticipate that bLF could be considered in the 
A

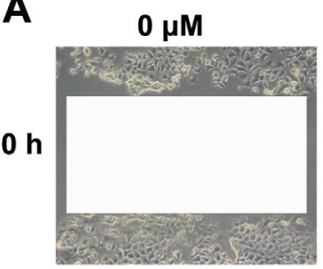

$175 \mu M$ BSA

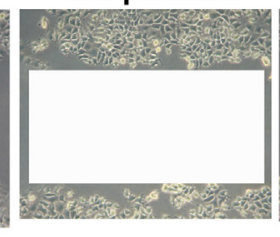

$175 \mu \mathrm{M}$ bLF
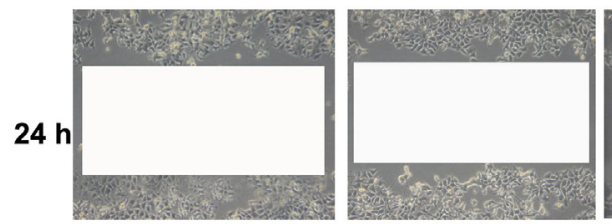

B

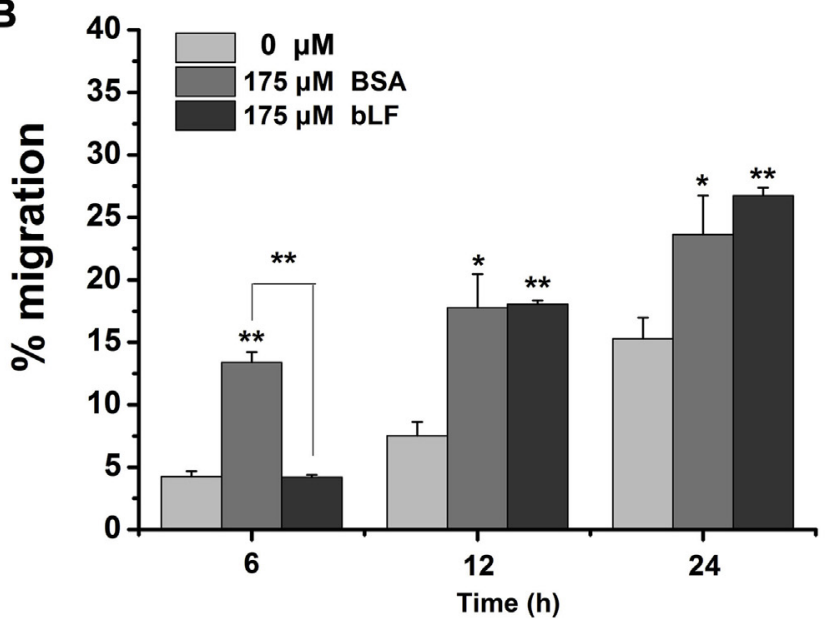

Fig. 6. Effect of bovine lactoferrin (bLF) on the migration of MCF-7 cells; cells were incubated with the same concentration of bLF and bovine serum albumin (BSA) for $6 \mathrm{~h}$, $12 \mathrm{~h}$ and $24 \mathrm{~h}$. Panel A: representative images of cell migration into the wounded area after $24 \mathrm{~h}$ of incubation (magnification: $40 \times$ ). Panel B: relative wound closure as measured by Image J software; results correspond to the mean \pm SD of three independent experiments; ${ }^{*} p<0.01$ and ${ }^{* *} p<0.01$ when compared with the control or among each other.

future as a potential nutraceutical for chemoprevention and/or cancer treatment.

\section{Conclusion}

In summary, the bLF effect against four breast cancer cell lines was evaluated in a concentration range from $12.5 \mu \mathrm{m}$ to $175 \mu \mathrm{m}$. The protein was found to selectively induce apoptosis in MCF-7 cells, as a delayed event that could only be observed at $40-48 \mathrm{~h}$ with mitochondria depolarisation and the presence of phosphatidylserine in the outer leaflet of plasma membrane, as well as at $72 \mathrm{~h}$ with DNA condensation and fragmentation. Furthermore, bLF significantly decreased the levels of the anti-apoptotic $\mathrm{Bcl}-2$ protein that, in addition to the mitochondrial membrane depolarisation, suggests that the intrinsic pathway may be involved in the apoptosis induction. The inhibitory effect of the milk protein on MCF-7 cells growth was also shown to be associated with the cell cycle arrest at the G1 phase. Lastly, the bLF anticancer potential against breast cancer cells was confirmed by its pronounced ability to inhibit colony formation.

\section{Acknowledgements}

Zhang Y. acknowledges the Erasmus Mundus External Cooperation window (Bridging the Gap) for supporting his PhD grant. The authors acknowledge the financial support from the Strategic Projects PEst-OE/EQB/LA0023/2013 and PEst-OE/AGR/UI4033/ 2014, as well as the project ref. RECI/BBB-EBI/0179/2012 (project number FCOMP-01-0124-FEDER-027462) funded by Fundação para a Ciência e a Tecnologia, Portugal.

\section{References}

Adlerova, L., Bartoskova, A., \& Faldyna, M. (2008). Lactoferrin: a review. Veterinarn Medicina, 53, 457-468.

Balcão, V. M., Costa, C. I., Matos, C. M., Moutinho, C. G., Amorim, M., Pintado, M. E., et al. (2013). Nanoencapsulation of bovine lactoferrin for food and biopharmaceutical applications. Food Hydrocolloids, 32, 425-432.

Bi, B. Y., Liu, J. L., Legrand, D., Roche, A. C., Capron, M., Spik, G., et al. (1996). Internalization of human lactoferrin by the Jurkat human lymphoblastic T-cell line European Journal of Cell Biology, 69, 288-296.

Breton, M., Mariller, C., Benaïssa, M., Caillaux, K., Browaeys, E., Masson, M., et al (2004). Expression of delta-lactoferrin induces cell cycle arrest. Biometals, 17, $325-329$.

Damiens, E., El Yazidi, I., Mazurier, J., Duthille, I., Spik, G., \& Boilly-Marer, Y. (1999). Lactoferrin inhibits G1 cyclin-dependent kinases during growth arrest of human breast carcinoma cells. Journal of Cellular Biochemistry, 74, 486-498.

De la Rosa, G., Yang, D., Tewary, P., Varadhachary, A., \& Oppenheim, J. J. (2008). Lactoferrin acts as an alarmin to promote the recruitment and activation of APCs and antigen-specific immune responses. Journal of Immunology, 180 6868-6876.

Dias, T. A., Duarte, C. L., Lima, C. F., Proença, M. F., \& Pereira-Wilson, C. (2013). Superior anticancer activity of halogenated chalcones and flavonols over the natural flavonol quercetin. European Journal of Medicinal Chemistry, 65, 500-510.

Duarte, D., Nicolau, A., Teixeira, J., \& Rodrigues, L. (2011). The effect of bovine milk lactoferrin on human breast cancer cell lines. Journal of Dairy Science, 94, 66-76.

Eliassen, L. T., Berge, G., Leknessund, A., Wikman, M., Lindin, I., Løkke, C., et al. (2006). The antimicrobial peptide, lactoferricin B, is cytotoxic to neuroblastoma cells in vitro and inhibits xenograft growth in vivo. International Journal of Cancer, 119, 493-500.

Elmore, S. (2007). Apoptosis: a review of programmed cell death. Toxicologic Pathology, 35, 495-516.

Fischer, R., Debbabi, H., Dubarry, M., Boyaka, P., \& Tome, D. (2006). Regulation of physiological and pathological Th1 and Th2 responses by lactoferrin. Biochemistry and Cell Biology, 84, 303-311.

Furlong, S. J., Mader, J. S., \& Hoskin, D. W. (2006). Lactoferricin-induced apoptosis in estrogen-nonresponsive MDA-MB-435 breast cancer cells is enhanced by C6 ceramide or tamoxifen. Oncology Reports, 15, 1385-1390.

Furmanski, P., Li, Z., Fortuna, M. B., Swamy, C., \& Das, M. R. (1989). Multiple molecular forms of human lactoferrin. Identification of a class of lactoferrins that possess ribonuclease activity and lack iron-binding capacity. Journal of Experimental Medicine, 170, 415-429.

Gottlieb, E., Armour, S., Harris, M., \& Thompson, C. (2003). Mitochondrial membrane potential regulates matrix configuration and cytochrome c release during apoptosis. Cell Death and Differentiation, 10, 709-717.

Ha, N.-H., Nair, V. S., Reddy, D. N. S., Mudvari, P., Ohshiro, K., Ghanta, K. S., et al (2011). Lactoferrin-endothelin-1 axis contributes to the development and invasiveness of triple-negative breast cancer phenotypes. Cancer Research, 71 7259-7269.

Hu, K., Shi, Y., Jiang, W., Han, J., Huang, S., \& Jiang, X. (2011). Lactoferrin conjugated PEG-PLGA nanoparticles for brain delivery: preparation, characterization and efficacy in Parkinson's disease. International Journal of Pharmacology, 415 273-283.

Jänicke, R. U. (2009). MCF-7 breast carcinoma cells do not express caspase-3. Breast Cancer Research and Treatment, 117, 219-221.

Jenssen, H., \& Hancock, R. E. (2009). Antimicrobial properties of lactoferrin. Biochimie, 91, 19-29.

Kappeler, S. R., Ackermann, M., Farah, Z., \& Puhan, Z. (1999). Sequence analysis of camel (Camelus dromedarius) lactoferrin. International Dairy Journal, 9 481-486.

Korhonen, H., \& Pihlanto, A. (2006). Bioactive peptides: production and functionality. International Dairy Journal, 16, 945-960.

Kuhara, T., Iigo, M., Itoh, T., Ushida, Y., Sekine, K., Terada, N., et al. (2000). Orally administered lactoferrin exerts an antimetastatic effect and enhances production of IL-18 in the intestinal epithelium. Nutrition and Cancer, 38, 192-199.

Kuhara, T., Yamauchi, K., \& Iwatsuki, K. (2012). Bovine lactoferrin induces interleukin-11 production in a hepatitis mouse model and human intestinal myofibroblasts. European Journal of Nutrition, 51, 343-351.

Lee, S. H., Park, S. W., Pyo, C. W., Yoo, N. K., Kim, J., \& Choi, S. Y. (2009). Requirement of the JNK-associated Bcl-2 pathway for human lactoferrin-induced apoptosis in the Jurkat leukemia T cell line. Biochimie, 91, 102-108.

Liao, Y., Du, X., \& Lönnerdal, B. (2010). miR-214 regulates lactoferrin expression and pro-apoptotic function in mammary epithelial cells. Journal of Nutrition, 140 $1552-1556$.

Liao, Y., Jiang, R., \& Lonnerdal, B. (2012). Biochemical and molecular impacts of lactoferrin on small intestinal growth and development during early life. Biochemistry and Cell Biology, 90, 476-484. 
Lin, T. Y., Chiou, S. H., Chen, M., \& Kuo, C. D. (2005). Human lactoferrin exerts bidirectional actions on PC12 cell survival via ERK1/2 pathway. Biochemical and Biophysical Research Communications, 337, 330-336.

Lonnerdal, B., Jiang, R., \& Du, X. (2011). Bovine lactoferrin can be taken up by the human intestinal lactoferrin receptor and exert bioactivities. Journal of Pediatric Gastroenterology and Nutrition, 53, 606-614.

Ly, J., Grubb, D., \& Lawen, A. (2003). The mitochondrial membrane potential ( $\Delta \Psi \mathrm{m}$ ) in apoptosis; an update. Apoptosis, 8, 115-128.

Mader, J. S., Salsman, J., Conrad, D. M., \& Hoskin, D. W. (2005). Bovine lactoferricin selectively induces apoptosis in human leukemia and carcinoma cell lines. Molecular Cancer Therapeutics, 4, 612-624.

Meulmeester, E., \& Jochemsen, A. G. (2008). p53: a guide to apoptosis. Current Cancer Drug Targets, 8, 87-97.

Norrby, K., Mattsby Baltzer, I., Innocenti, M., \& Tuneberg, S. (2001). Orally administered bovine lactoferrin systemically inhibits $\mathrm{VEGF}_{165}$-mediated angiogenesis in the rat. International Journal of Cancer, 91, 236-240.

Onishi, J., Roy, M. K., Juneja, L. R., Watanabe, Y., \& Tamai, Y. (2008). A lactoferrinderived peptide with cationic residues concentrated in a region of its helical structure induces necrotic cell death in a leukemic cell line (HL-60). Journal of Peptide Science, 14, 1032-1038.

Rodrigues, L. R. (2013). Milk minor constituents, enzymes, hormones, growth factors, and organic acids. In Y. W. Park, \& G. F. W. Haenlein (Eds.), Milk and dairy products in human nutrition (Vol. 11, pp. 220-245). Somerset, NJ, USA: WileyBlackwell.

Roy, M., Kuwabara, Y., Hara, K., Watanabe, Y., \& Tamai, Y. (2002). Peptides from the $\mathrm{N}$-terminal end of bovine lactoferrin induce apoptosis in human leukemic (HL60) cells. Journal of Dairy Science, 85, 2065-2074.

Sakai, T., Banno, Y., Kato, Y., Nozawa, Y., \& Kawaguchi, M. (2005). Pepsin-digested bovine lactoferrin induces apoptotic cell death with JNK/SAPK activation in oral cancer cells. Journal of Pharmacological Sciences, 98, 41-48.
Syed, D. N., Khan, N., Afaq, F., \& Mukhtar, H. (2007). Chemoprevention of prostate cancer through dietary agents: progress and promise. Cancer Epidemiology Biomarkers and Prevention, 16, 2193-2203.

Valster, A., Tran, N. L., Nakada, M., Berens, M. E., Chan, A. Y., \& Symons, M. (2005). Cell migration and invasion assays. Methods, 37, 208-215.

Wakabayashi, H., Yamauchi, K., \& Takase, M. (2006). Lactoferrin research, technology and applications. International Dairy Journal, 16, 1241-1251.

Wang, J., Li, Q., Ou, Y., Han, Z., Li, K., Wang, P., et al. (2011). Inhibition of tumor growth by recombinant adenovirus containing human lactoferrin through inducing tumor cell apoptosis in mice bearing EMT6 breast cancer. Archives of Pharmacal Research, 34, 987-995.

Wang, J., Li, Q., Ou, Y., Li, K., Han, Z., Wang, P., et al. (2012). Recombination adenovirus-mediated human lactoferrin cDNA inhibits the growth of human MCF-7 breast cancer cells. Journal of Pharmacy and Pharmacology, 64, $457-463$.

Xu, X., Jiang, H., Li, H., Zhang, T., Zhou, O. \& Liu, N. (2010). Apoptosis of stomach cancer cell SGC-7901 and regulation of Akt signaling way induced by bovine lactoferrin. Journal of Dairy Science, 93, 2344-2350.

Xu, H., Shan, J., Jurukovski, V., Yuan, L., Li, J., \& Tian, K. (2007). TSP50 encodes a testis-specific protease and is negatively regulated by p53. Cancer Research, 67, 1239-1245.

Yamada, Y., Sato, R., Kobayashi, S., Hankanga, C., Inanami, O., Kuwabara, M., et al. (2008). The antiproliferative effect of bovine lactoferrin on canine mammary gland tumor cells. Journal of Veterinary Medical Science/Japanese Society of Veterinary Science, 70, 443.

Zhou, Y., Zeng, Z., Zhang, W., Xiong, W., Wu, M., Tan, Y., et al. (2008). Lactotransferrin: a candidate tumor suppressor-Deficient expression in human nasopharyngeal carcinoma and inhibition of NPC cell proliferation by modulating the mitogen-activated protein kinase pathway. International Journal of Cancer, 123, 2065-2072. 